\title{
Study of the role of the transcranial magnetic stimulation on language progress in autism spectrum disorder
}

\author{
Mohamed E. Darwish ${ }^{1 *}$, Heba W. El-Beshlawy ${ }^{1}$, Ehab S. Ramadan² and Shimaa M. Serag ${ }^{1}$
}

\begin{abstract}
Background: Children with autism spectrum disorder (ASD) are almost universally delayed in the acquisition of spoken language as primary means of communication so they tend to have restricted outcomes in terms of independence and integration. Transcranial magnetic stimulation (TMS) is a promising, emerging tool for the study (study and modulate excitability and plasticity, applied in single pulses to investigate corticospinal excitability, pairs of pulses to study intracortical inhibition and facilitation) and potential treatment of ASD. The purpose of this study is to evaluate the role of repetitive TMS in language progress in children with ASD.

Results: There was a statistically significant clinical improvement in patients receiving active TMS (group I) comparing baseline Childhood Autism Rating Scale (CARS) assessment and after treatment $(P \leq 0.05)$. There was mild improvement with no significant difference between the patients receiving active TMS (group I) and those of sham TMS (group II), and both groups received language therapy as regard post-treatment CARS. There was significant difference in improvement between the two groups according to eye contact $(P \leq 0.05)$. There was significant improvement in response to examiner $(P \leq 0.05)$. There was mild improvement with no statistically significant difference in attention between the two groups. There was significant difference in improvement between the two groups according to active expressive language. There was no statistically significant difference in passive vocabulary between the two groups.

Conclusion: Repetitive transcranial magnetic stimulation (rTMS) over left inferior frontal gyrus may be a safe and effective way of improving language of ASD. The joint application of rTMS and standard language therapy may lead to more rapid improvement in the language progress of children with ASD.
\end{abstract}

Keywords: Transcranial, Autism, Magnetic stimulation, Language

\section{Background}

Autism spectrum disorder (ASD) is a neurodevelopmental condition. Core ASD signs include social contact impairments and limited and repeated habits and actions starting in the early developmental period [1]. Most patients with ASD are given psychotropic drugs somewhere in their lives [2].

\footnotetext{
* Correspondence: mohameddarwish@hotmail.com

${ }^{1}$ Phoniatrics Department, Faculty of Medicine, Tanta University, Tanta, El-Gharbia, Egypt

Full list of author information is available at the end of the article
}

ASD evaluation is focused on findings and behavioral evaluations using psychiatric disorder Diagnostic and Statistical Manual (DSM) or International Disease Classification (ICD) guidelines. The brain networks responsible for high-level abilities that are compromised as part of core ASD features are complicated, needing several brain regions to be incorporated effectively. Thus, ASD pathophysiology is definitely a failure of long-range neuronal circuit functioning and integration [3]. ASD language skills can vary from nonverbal to strongly idiosyncratic language with echolalia. Therefore, any effort

\section{Springer Open}

(c) The Author(s). 2021 Open Access This article is licensed under a Creative Commons Attribution 4.0 International License, which permits use, sharing, adaptation, distribution and reproduction in any medium or format, as long as you give appropriate credit to the original author(s) and the source, provide a link to the Creative Commons licence, and indicate if changes were made. The images or other third party material in this article are included in the article's Creative Commons licence, unless indicated otherwise in a credit line to the material. If material is not included in the article's Creative Commons licence and your intended use is not permitted by statutory regulation or exceeds the permitted use, you will need to obtain permission directly from the copyright holder. To view a copy of this licence, visit http://creativecommons.org/licenses/by/4.0/. 
to induce speech in preverbal children with ASD for social interactions and later life is important [4].

Transcranial magnetic stimulation (TMS) is a noninvasive focal brain stimulation system where localized intracranial electrical currents, strong enough to depolarize a limited neuron population, are produced by rapidly shifting magnetic fields [5]. TMS may be a novel rehabilitation tool for ASD [6]. TMS may be applied in single pulses, pulses, or repeated pulses (rTMS). TMS is safe and well-tolerated [7].

This research aimed to assess the role of repeated TMS in language progress in ASD children.

\section{Methods}

This randomized control clinical study was carried out on thirty autistic patients (20 males and 10 females); their ages ranged between 3 and 10 years, as this is the age of language production; after this age, no improvement in language is achieved. These cases presented to the outpatient clinic of the Phoniatric Unit and affiliated hospitals during the period from October 2018 to October 2019 after obtaining permission from institutional ethical committee, and an informed consent was taken from parents of all patients.

The exclusion criteria included the following: age above 10 years and below 3 years; other diseases affecting language development as hearing impairment and brain damaged motor handicapped (BDMH); any contraindications to TMS such as epilepsy, history of neurosurgical operations, those with metal material as pacemakers and plates, as in cochlear implant, receive tranquilizers, who refused to be enrolled in the study, and under other lines of treatment.

Patients were randomly classified with computergenerated random numbers and sealed opaque envelops into two equal groups (15 patients): group I was subjected to rTMS and language therapy, and group II was subjected to sham TMS and language therapy. All patients were subjected to the following: (I) elementary diagnostic procedures: (A) parents' interview and full careful history taking including personal history; complaint and analysis of the symptoms; prenatal, natal, and postnatal history; developmental history; history of present illness: core features of ASD, past history, and family history of similar condition. (B) General examination. (C) Vocal tract examination. (D) Ear and nose examination. (E) Neurological examination, to exclude any neurological deficits. (II) Clinical diagnostic aids: (A) psychometry: Childhood Autism Rating Scale (CARS) [8] was done before and after treatment; as regards mentality, we do not make IO tests for autistic children as it is masked by their hyperactivity and stereotype repetitive movements. (B) Audiological evaluation: using pure tone audiometry and confirmatory evoked response audiometry, if needed. (C) Language evaluation: using Arabic language test [9] including assessment of eye contact, response to examiner and obey simple order, attention evaluation, and passive and active language assessment before and after treatment. (III) TMS protocol: patients received real TMS or sham stimulation at the Psychiatry and Neurology Center, Tanta University Hospital (TUH). The rTMS is administered weekly for 4 weeks over the left inferior frontal cortex (IFC). TMS is administered at low frequency of $1.0 \mathrm{~Hz}$ and $70 \%$ of the motor threshold (MT), total of 1800 pulses per day session with 20 trains with 90 pulses each. There will be 20-s intervals between the trains. The duration of each session is $40 \mathrm{~min}$. Trial stimulation is administered exactly according to the international 10-20 EEG electrode position stimulation.

\section{Stimulation site}

Broca's region in the left inferior frontal gyrus (LIFG) represented as F5 in the 10-20 system of EEG electrode positioning

\section{Calculation of the motor threshold (MT) of each patient}

MT is established for each hemisphere of all participants with autism by growing the stimulator performance by $5 \%$ before the first dorsal interosseous twitch is noticeable.

Sham stimulation was provided at the same position, power, and frequency with the coil angled $45^{\circ}$ from the skull which produced intracerebral voltage around $1 / 3$ of active TMS stimulation.

\section{Language therapy sessions}

It was done for groups I and II; each patient received three sessions per week. The session was divided in two phases: a practice phase and an activity phase as follows: (1) practice phase, estimated time (15-20 min). Put three cards of different semantic groups on the table (e.g., cat, banana, and ball) then ask the child in clear voice to give one card at a time to make sure that the child knows them. (2) Activity phase, estimated time (20 min). Highly motivating activities were used, e.g., crushing cars, pretend cooking, and building blocks. The aim was to help children to like the playful movements and expression produced by the clinician. Language therapy continued for 3 months.

\section{Statistical analysis}

Data was obtained, coded, tabulated, and entered into Social Sciences Statistical Package (IBM SPSS) version 21. Data normality was first tested with Shapiro-Wilk test. There are two forms of statistical analysis: (1) quantitative data: mean and standard deviation for parametric data. Median, minimum, and maximum were calculated for non-parametric data. (2) Qualitative data were represented using frequency and ratio. Data comparison of 
two matched groups (pre and post) was performed using Wilcoxon quantitative data test and chi-squared qualitative data test. $P<0.05$ was deemed important.

\section{Results}

As regards demographic data (age and gender), there were insignificant differences between the two groups (Table 1).

There is no significant difference between the two groups as regards baseline psychometric assessment before starting TMS sessions by CARS scale. As regard post-treatment, CARS shows that there was mild improvement with no significant difference between the two groups. There is statistically significant clinical improvement in group I comparing baseline CARS assessment and after treatment for the same group (Table 2, $P$ $\left.\leq 0.05^{*}\right)$.

There is no significant difference between the two groups as regard baseline clinical evaluation according to eye contact, response to examiner, obeying simple orders, and attention. Post-treatment clinical evaluation showed significant improvement between the two groups according to eye contact $\left(P \leq 0.05^{*}\right)$. In group I, patients with poor eye contact were $6.6 \%$, while in group II were $46.7 \%$. According to good eye contact, better results were achieved in group I (33.3\%) than in group II (13.3\%). There is significant improvement in response to examiner $\left(P \leq 0.05^{*}\right)$ as $60 \%$ of group II had no response in comparison with $13 \%$ in group I, while $33.3 \%$ of group I had good response versus 6.7\% in group II. According to attention, there was mild improvement with no statistically significant difference between the two groups. As regard obey simple order parameter, there was no change between the two groups (Figs. 1 and 2).

There was no significant difference between the two groups as regard baseline language evaluation according to passive vocabulary and active vocabulary (expressive language). After treatment language evaluation, there is significant difference in improvement between the two groups according to active expressive language as

Table 1 Sociodemographic data for patients enrolled in the study

\begin{tabular}{|c|c|c|c|c|c|c|}
\hline \multirow{2}{*}{$\begin{array}{l}\text { Characteristics } \\
\text { Age (in years) }\end{array}$} & \multicolumn{2}{|c|}{$\begin{array}{l}\text { Group I } \\
(n=15)\end{array}$} & \multicolumn{2}{|c|}{$\begin{array}{l}\text { Group II } \\
(n=15)\end{array}$} & \multirow{3}{*}{$\begin{array}{c}\text { Sig. test } \\
t \\
-1.026\end{array}$} & \multirow{2}{*}{$\begin{array}{l}\boldsymbol{P} \\
0.313\end{array}$} \\
\hline & & & & & & \\
\hline Mean \pm SD & \multicolumn{2}{|c|}{$5.13 \pm 1.89$} & \multicolumn{2}{|c|}{$5.92 \pm 2.33$} & & \\
\hline Range & \multicolumn{2}{|c|}{$3.0-10.0$} & \multicolumn{2}{|c|}{$3.0-10.0$} & & \\
\hline \multicolumn{5}{|l|}{ Gender } & $x^{2}$ & 0.946 \\
\hline Female & 4 & $26.7 \%$ & 6 & $40.0 \%$ & & \\
\hline Male & 11 & $73.3 \%$ & 9 & $60.0 \%$ & & \\
\hline
\end{tabular}

$X^{2}$ chi-squared test, $t$ independent sample t test, Sig. significant, $n$ number, $\%$ percentage nonverbal patients in group II were 53.3\%, while in group I were $6.7 \%$. Patients who could utter one single word in group I were $6.7 \%$ while in group II were $13.3 \%$. Patients who could utter $2-5$ single words were equal in both groups $13.3 \%$. There was significant difference between the two groups as regard patients who uttered 610 words, as in group I there were $46.7 \%$, while in group II there were $6.7 \%$. As regard patients who uttered more than 10 words, there were $26.7 \%$ in group I while $13.3 \%$ in group II. According to the passive vocabulary, there was mild improvement but with no statistically significant difference between the two groups (Tables 3 and 4)

\section{Discussion}

TMS is a successful, new method for researching and handling ASD. Recent studies indicate that TMS measurements include rapid, non-invasive markers of ASD pathophysiology. Moreover, repeated TMS (rTMS) could be an innovative therapeutic technique to reduce any of the central and related ASD symptoms [3].

In our research, we used rTMS on Broca's LIFG region to strengthen language and speech disabilities in ASD, as this area is classically called a motor speech-producing area and involved in learning and imitating behavior. It also appears to support sequencing behavior. Broca's area may have developed for inter-individual contact through movements and voice. Speech development and interpretation can be called a highly evolved method of action execution/observation matching, and this is one of the broad range of functions served by Broca's area, in line with Nishitani et al. [10]. Like Fecteau et al. [11] who used identical, standard TMS procedure in a shamcontrolled study in 10 adults with Asperger Syndrome (ASP) and 10 safe participants. They selected Broca's area then subdivided it into opercular pars and triangular pars; however, we stimulated Broca's area as a whole in our study [11]. Marangolo [12] opted for the same region except for the care of patients with chronic aphasia, and the findings ensured that the treatment enhanced informative expression in people with chronic aphasia [12]. In comparison to our research, Yang et al. [13] and Assadi [14] stimulated the left lower parietal lobule (leftIPL), which is closely linked to other cortical regions by white matter tracts like the upper longitudinal fascicle, which plays an important role in the processing of affective faces, as well as the arcuate fasciculus, which is very important for the visuospatial and language. Targeting the left-IPL region in this way provides the potential of treating instability in the mirror neuron system as well as language and affective processing impairments $[13,14]$.

In our research, we used unilateral rTMS on the left side of Broca when Fecteau et al. [11] used bilateral rTMS, and their contrast between right and left showed 
Table 2 Comparison between baseline CARS assessment and after treatment

\begin{tabular}{|c|c|c|c|c|c|c|c|}
\hline \multirow[t]{2}{*}{ CARS } & & \multicolumn{2}{|c|}{$\begin{array}{l}\text { Group I } \\
(n=15)\end{array}$} & \multicolumn{2}{|c|}{$\begin{array}{l}\text { Group II } \\
(n=15)\end{array}$} & \multirow[t]{2}{*}{$x^{2}$} & \multirow[t]{2}{*}{$P$} \\
\hline & & $\mathrm{N}$ & $\%$ & $\mathrm{~N}$ & $\%$ & & \\
\hline \multirow[t]{3}{*}{ Baseline } & Non-autistic & 0 & $0 \%$ & 0 & $0 \%$ & 1.222 & 0.269 \\
\hline & Mild to moderate & 10 & $66.7 \%$ & 7 & $46.7 \%$ & & \\
\hline & Moderate to severe & 5 & $33.3 \%$ & 8 & $53.3 \%$ & & \\
\hline \multirow[t]{5}{*}{ After treatment } & Non-autistic & 4 & $26.7 \%$ & 2 & $13.3 \%$ & 0.844 & 0.789 \\
\hline & Mild to moderate & 7 & $46.7 \%$ & 8 & $53.3 \%$ & & \\
\hline & Moderate to severe & 4 & $26.7 \%$ & 5 & $33.3 \%$ & & \\
\hline & & \multicolumn{2}{|c|}{6.189} & \multicolumn{2}{|c|}{2.759} & & \\
\hline & D & \multicolumn{2}{|c|}{$0.045^{*}$} & \multicolumn{2}{|c|}{0.252} & & \\
\hline
\end{tabular}

$X^{2}$ chi-squared test, CARS Childhood Autism Rating Scale, $n$ number, $\%$ percentage

*Significant, $P \leq 0.05$

that rTMS to left pars triangularis substantially enhanced ASP volunteer naming performance [11]. In current study, rTMS was driven by an international 1020 EEG method that is more relevant, unlike Fecteau et al. [11], by anatomical brain magnetic resonance imaging of each person, which is more effective in detecting brain region [9]. One $\mathrm{Hz}$ was chosen as the stimulation frequency and $70 \%$ strength of stimulatory production as other related studies such as Fecteau et al. [11], who reported that this form of stimulation holds the stimulation power below MT as an extra protection safeguard due to the increased risk of seizure in this sample population [11]. George et al. [15] found another ethical issue relevant to adding rTMS to a pediatric brain that is still under construction. It is widely understood that a child's brain is not only a smaller version of an adult brain, and clinical treatments such as rTMS may have unique, unexpected, and possibly longlasting impact on neurodevelopment [15]. Unlike our study, Yang et al. [13] and Assadi [14] used high frequency rTMS and $80 \%$ strength of stimulatory production, but in older age groups ranging from 17 years of age $[13,14]$.

With respect to concentration and adherence to basic commands, there is no substantial gap in relation between the two groups, and that was predicted since our research did not target their particular brain regions. While in other research including Gómez et al. [16] and Abd alrahman et al. [17] who used CARS in evaluation. Even Abd alrahman et al.'s [17] findings demonstrated a

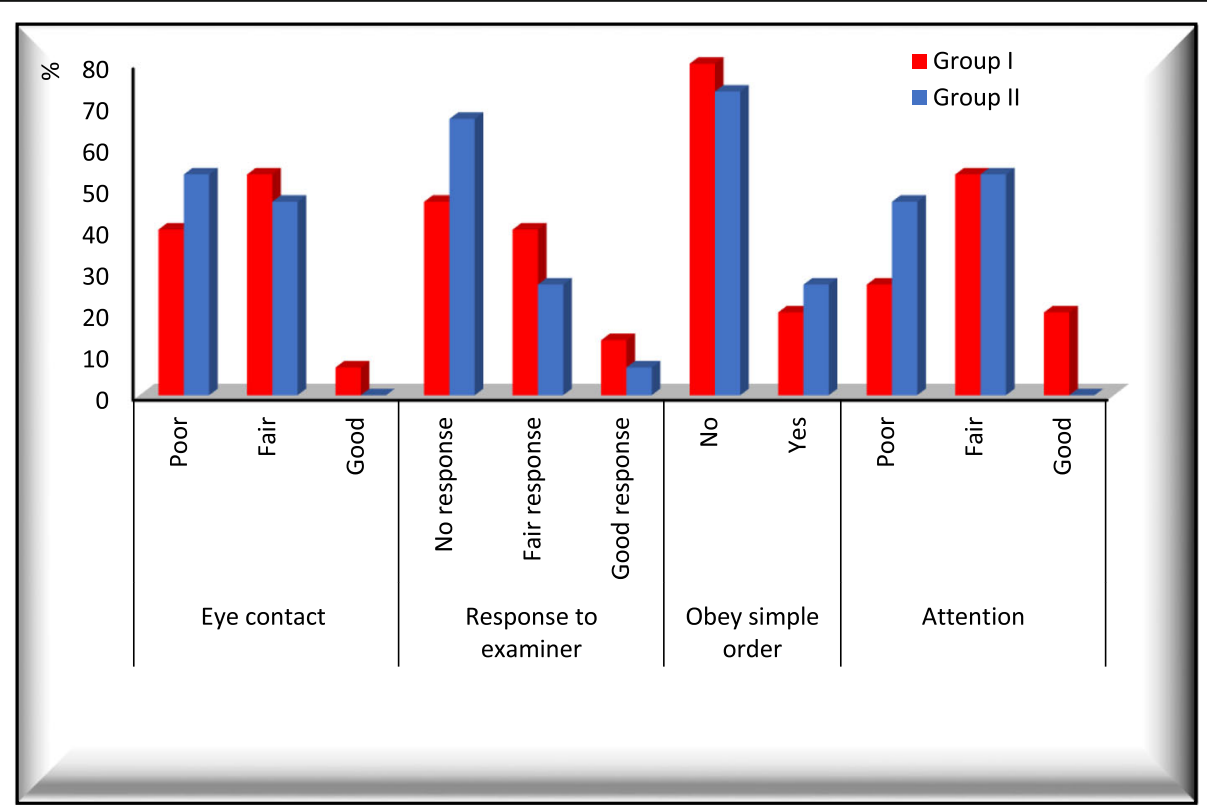

Fig. 1 Comparison between the two groups as regard baseline clinical evaluation 


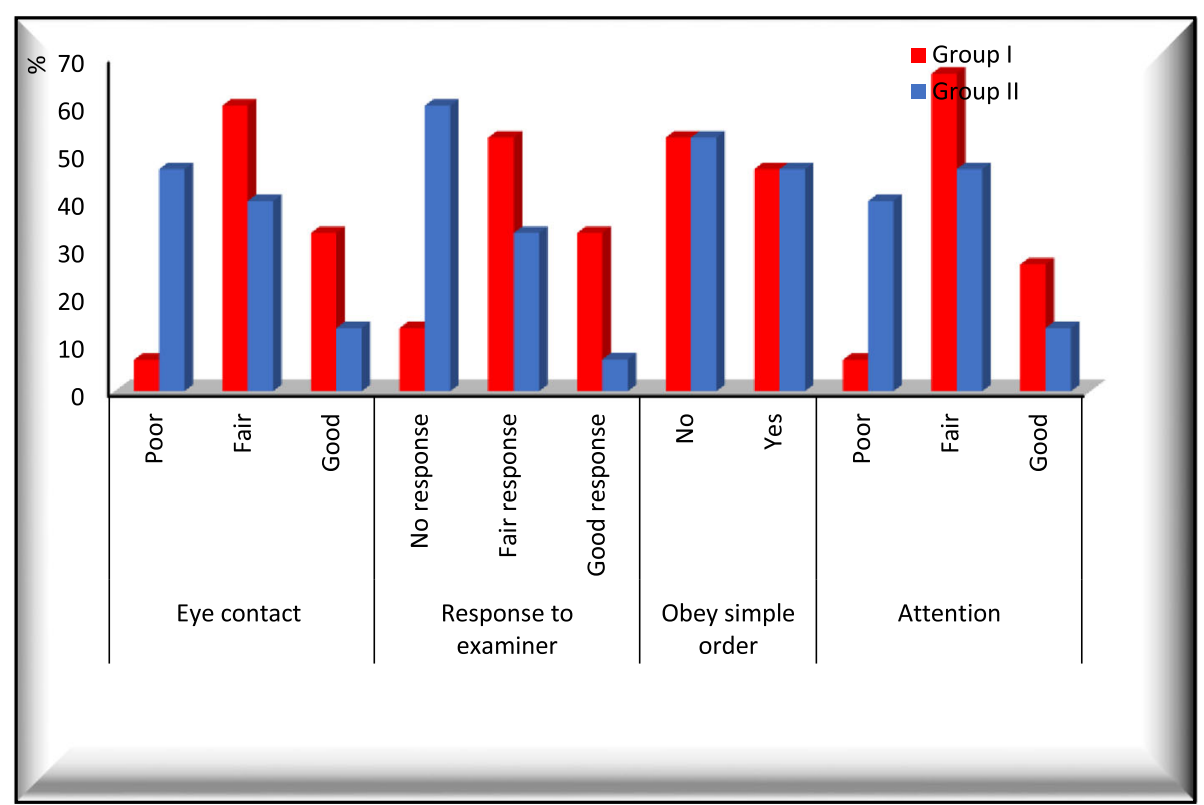

Fig. 2 After treatment clinical evaluation between the two groups

substantial increase in the seriousness of clinical symptoms for ASD except for activity level and body reaction and use [17]. Gómez et al.'s [16] findings also demonstrated substantial decrease in repeated activity and less significant change in social deficits. Both preferred dorsolateral prefrontal cortex (DLPFC) stimulation for behavior improvement [16].

Our research used the Arabic language test to assess language learning as a whole. Thus, Assadi [14] used the evaluation scale expressive vocabulary measure and the Delis-Kaplan Executive Function Method (D-KEFS) Verbal Fluency challenge (D-KEFS Verbal Fluency) and tested expressive language only [14]. Regarding language evaluation, there was a minor clinical increase in passive language assessment with no statistical meaning as we were not targeting the Wernicke region. However, active expressive language in group I was substantially increased, and this was predicted to provide better effect relative to group II due to the selection of proper age, brain region, and suitable stimulus level $\left(P 0.05^{*}\right)$. As reported by Fecteau et al. [11], using rTMS to the left pars triangularis significantly improved the naming output of ASP volunteers [9]. Even Yang et al. [13] and Assadi [14] have enhanced language abilities, while they used high frequency rTMS targeting mirror neurons in the left lower parietal lobule (left-IPL) with possibly improved social responsiveness [13, 14]. Additionally, Marachev and Grigorieva [18] demonstrated quicker dynamic

Table 3 Baseline language evaluation

\begin{tabular}{|c|c|c|c|c|c|c|c|}
\hline \multicolumn{2}{|c|}{ Baseline language evaluation } & \multicolumn{2}{|c|}{$\begin{array}{l}\text { Group I } \\
(n=15)\end{array}$} & \multicolumn{2}{|c|}{$\begin{array}{l}\text { Group II } \\
(n=15)\end{array}$} & \multirow[t]{2}{*}{$x^{2}$} & \multirow[t]{2}{*}{$\mathbf{P}$} \\
\hline & & $\mathbf{N}$ & $\%$ & $\mathrm{~N}$ & $\%$ & & \\
\hline \multirow[t]{5}{*}{ Passive vocab } & Poor in all parameters & 1 & $6.7 \%$ & 5 & $33.3 \%$ & \multirow[t]{5}{*}{3.611} & \multirow[t]{5}{*}{0.167} \\
\hline & Know family members & 2 & $13.3 \%$ & 1 & $6.7 \%$ & & \\
\hline & Know $1-5 / 20$ semantic components & 5 & $33.3 \%$ & 4 & $26.7 \%$ & & \\
\hline & Know 5-10/20 & 2 & $13.3 \%$ & 2 & $13.3 \%$ & & \\
\hline & More than 10 & 5 & $33.3 \%$ & 3 & $20.0 \%$ & & \\
\hline \multirow{5}{*}{$\begin{array}{l}\text { Active vocab } \\
\text { Expressive language }\end{array}$} & Non-verbal & 3 & $20.0 \%$ & 8 & $53.3 \%$ & \multirow[t]{5}{*}{4.549} & \multirow[t]{5}{*}{0.337} \\
\hline & 1 single word & 4 & $26.7 \%$ & 3 & $20.0 \%$ & & \\
\hline & $2-5$ & 4 & $26.7 \%$ & 1 & $6.7 \%$ & & \\
\hline & $5-10$ & 2 & $13.3 \%$ & 1 & $6.7 \%$ & & \\
\hline & More than 10 words & 2 & $13.3 \%$ & 2 & $13.3 \%$ & & \\
\hline
\end{tabular}


Table 4 After treatment language evaluation

\begin{tabular}{|c|c|c|c|c|c|c|c|}
\hline \multicolumn{2}{|c|}{ After treatment language evaluation } & \multicolumn{2}{|c|}{$\begin{array}{l}\text { Group I } \\
(n=15)\end{array}$} & \multicolumn{2}{|c|}{$\begin{array}{l}\text { Group II } \\
(n=15)\end{array}$} & \multirow[t]{2}{*}{$x^{2}$} & \multirow[t]{2}{*}{$\mathbf{P}$} \\
\hline & & $\mathrm{N}$ & $\%$ & $\mathrm{~N}$ & $\%$ & & \\
\hline \multirow[t]{5}{*}{ Passive vocab } & Poor in all parameters & 1 & $6.7 \%$ & 4 & $26.7 \%$ & \multirow[t]{5}{*}{8.179} & \multirow[t]{5}{*}{0.085} \\
\hline & Know family members & 1 & $6.7 \%$ & 1 & $6.7 \%$ & & \\
\hline & Know $1-5 / 20$ semantic components & 1 & $6.7 \%$ & 5 & $33.3 \%$ & & \\
\hline & Know 6-10/20 & 3 & $20.0 \%$ & 2 & $13.3 \%$ & & \\
\hline & More than 10 & 9 & $60.0 \%$ & 3 & $20.0 \%$ & & \\
\hline \multirow{5}{*}{$\begin{array}{c}\text { Active vocab } \\
\text { Expressive language }\end{array}$} & Non-verbal & 1 & $6.7 \%$ & 8 & $53.3 \%$ & \multirow[t]{5}{*}{10.944} & \multirow[t]{5}{*}{$0.027^{*}$} \\
\hline & 1 single word & 1 & $6.7 \%$ & 2 & $13.3 \%$ & & \\
\hline & $2-5$ & 2 & $13.3 \%$ & 2 & $13.3 \%$ & & \\
\hline & $6-10$ & 7 & $46.7 \%$ & 1 & $6.7 \%$ & & \\
\hline & More than 10 words. & 4 & $26.7 \%$ & 2 & $13.3 \%$ & & \\
\hline
\end{tabular}

$x^{2}$ chi-squared test, $n$ number, $\%$ percentage

*Statistically significant, $P \leq 0.05$

change in speech function, better focus, and behavioral order, while utilizing high frequency rTMS over DLPFC paired with normal speech therapy [18]. However, Fecteau et al. [11] noted a major deterioration in the name efficiency of ASP volunteers when rTMS addressed left pars orbicularis [11]. One of the limitations in this study was the small sample size. Also, the study protocol was 4 sessions of TMS, and further studies are needed to investigate its long-term outcome in these patients, in addition to choosing 10-20 EEG international system to localize Broca's area, and future studies should combine brain stimulation with neuroimaging techniques to be more accurate such as TMS-position emission tomography and TMS-functional magnetic resonance imaging.

\section{Conclusion}

Repetitive TMS over left frontal gyrus can be a safe and efficient way to enhance ASD vocabulary. Joint use of rTMS and standard language therapy can contribute to faster change in children's language progress with ASD.

\section{Abbreviations}

ASD: Autism spectrum disorder; TMS: Transcranial magnetic stimulation; CARS: Childhood Autism Rating Scale; ICD: International Classification of Diseases; IFC: Inferior frontal cortex; MT: Motor threshold; FDI: First dorsal interosseous; IBM SPSS: Statistical Package for Social Sciences; LIFG: Left inferior frontal gyrus; ASP: Asperger syndrome; Left IPL: Left inferior parietal lobule; DLPFC: Dorsal lateral prefrontal cortex; D-KEFS: Delis-Kaplan Executive Function System; D-KEFS Verbal Fluency: Verbal Fluency task

\section{Acknowledgements}

Not applicable

\section{Authors' contributions}

ER of Psychiatry Department has role in design. Assistant prof. MD and HB and lecturer of Phoniatrics Dr SS have an equal role in design, work, statistical analysis, and manuscript writing. The authors read and approved the manuscript for publication.

\section{Funding}

This research received no specific grant from any funding agency in the public, commercial, or not-for-profit sectors.

\section{Availability of data and materials}

All data generated or analyzed during this study are included in this published article [and its supplementary information files].

\section{Declarations}

Consent for the publication

Consent for the publication of this data was given by their parents or legal guardian; this was a written consent from all cases examined.

\section{Ethics approval and consent to participate}

A quasi-experimental study was carried out following the approval of the Research Ethical Committee of Faculty of Medicine, Phoniatrics Unit, Tanta University, (reference no. is not applicable) on thirty autistic patients (20 males and 10 females); their ages ranged between 3 and 10 years, presented to the outpatient clinic of the Phoniatrics Unit, Tanta University Hospitals, and affiliated hospitals during the period from October 2018 to October 2019. All patients' parent or legal guardians were informed about the aim of the study, and the procedure was fully explained to them. A written informed consent was taken from each child's parents that they know the type of evaluation and training and the duration of the given training program given to their child.

\section{Competing interests}

The authors declare that they have no competing interests.

\section{Author details}

${ }^{1}$ Phoniatrics Department, Faculty of Medicine, Tanta University, Tanta, El-Gharbia, Egypt. ${ }^{2}$ Psychiatry Department, Faculty of Medicine, Tanta University, Tanta, El-Gharbia, Egypt.

Received: 27 September 2020 Accepted: 10 May 2021

Published online: 09 June 2021

\section{References}

1. Association AP (2013) Diagnostic and statistical manual of mental disorders $\left(\mathrm{DSM}-5^{\circledR}\right)$. American Psychiatric Pub. https://doi.org/10.1176/appi.books. 9780890425596

2. Howes OD, Rogdaki M, Findon JL, Wichers RH, Charman T, King BH, Loth E, McAlonan GM, McCracken JT, Parr JR, Povey C, Santosh P, Wallace S, Simonoff E, Murphy DG (2018) Autism spectrum disorder: consensus guidelines on assessment, treatment and research from the British 
Association for Psychopharmacology. J Psychopharmacol 32(1):3-29. https:// doi.org/10.1177/0269881117741766

3. Oberman LM, Enticott PG, Casanova MF, Rotenberg A, Pascual-Leone A, McCracken JT et al (2016) Transcranial magnetic stimulation in autism spectrum disorder: challenges, promise, and roadmap for future research. Autism Res 9(2):184-203. https://doi.org/10.1002/aur.1567

4. Mody M, Belliveau JW (2013) Speech and language impairments in autism: insights from behavior and neuroimaging. N Am J Med Sci 5:157-160

5. Wagner T, Valero-Cabre A, Pascual-Leone A (2007) Noninvasive human brain stimulation. Annu Rev Biomed Eng 9(1):527-565. https://doi.org/10.1146/a nnurev.bioeng.9.061206.133100

6. Oberman LM, Rotenberg A, Pascual-Leone A (2015) Use of transcranial magnetic stimulation in autism spectrum disorders. J Autism Dev Disord 45(2):524-536. https://doi.org/10.1007/s10803-013-1960-2

7. Hong YH, Wu SW, Pedapati EV, Horn PS, Huddleston DA, Laue CS et al (2015) Safety and tolerability of theta burst stimulation vs. single and paired pulse transcranial magnetic stimulation: a comparative study of 165 pediatric subjects. Front Hum Neurosci 9:29-35

8. Schopler E, Reichler R, DeVellis R, Daly K (1980) Toward objective classification of childhood autism: childhood autism rating scale (CARS). J Autism Dev Disord 10(1):91-103. https://doi.org/10.1007/BF02408436

9. Kotby MN, Khairy A, Barakah M, Rifaie N, El-Shobary A (1995) August. Language testing of Arabic speaking children. In: Proceedings of the XXIII world congress of the International Association of Logopedics and Phoniatrics, pp 236-266

10. Nishitani N, Schürmann M, Amunts K, Hari R (2005) Broca's region: from action to language. Physiology (Bethesda, Md) 20:60-69

11. Fecteau S, Agosta S, Oberman L, Pascual-Leone A (2011) Brain stimulation over Broca's area differentially modulates naming skills in neurotypical adults and individuals with Asperger's syndrome. Eur J Neurosci 34(1):158164. https://doi.org/10.1111/j.1460-9568.2011.07726.x

12. Marangolo P (2013) tDCS over the left inferior frontal cortex improves speech production in aphasia. Front Hum Neurosci 7:539-555

13. Yang $Y$, Wang $H$, Xue Q, Huang Z, Wang Y (2019) High-frequency repetitive transcranial magnetic stimulation applied to the parietal cortex for lowfunctioning children with autism spectrum disorder: a case series. Front Psych 10:293-300. https://doi.org/10.3389/fpsyt.2019.00293

14. Assadi M, Dave J, Leone P, Redjal N, Curtin A (2020) Enhancement of behavioral and linguistic outcome measures in autism spectrum disorder through neuro-navigated transcranial magnetic stimulation: a pilot study. J Clin Neurosci 74:151-154. https://doi.org/10.1016/j.jocn.2020.02.005

15. George MS, Belmaker RH (2007) Transcranial magnetic stimulation in clinical psychiatry. American Psychiatric Pub, p R12

16. Gómez L, Vidal B, Maragoto C, Morales LM, Berrillo S, Vera Cuesta H, Baez M, Denis M, Marín T, Cabrera Y, Sánchez A, Alarcón C, Selguera M, Llanez Y, Dieguez L, Robinson M (2017) Non-invasive brain stimulation for children with autism spectrum disorders: a short-term outcome study. Behav Sci 7(3): 63. https://doi.org/10.3390/bs7030063

17. Abd Alrahman Al, AAM G, Elfekey TIM (2019) Study of the effect of repetitive transcranial magnetic stimulation on a sample of children with autism spectrum disorder. Egyptian J Hospital Med 76(7):4493-4498. https:// doi.org/10.21608/ejhm.2019.44832

18. Marachev M, Grigorieva A (2019) The use of transcranial magnetic stimulation in autistic spectrum disorders with predominance of speech impairment. Brain Stimul: Basic, Transl Clin Res Neuromodul 12:579

\section{Publisher's Note}

Springer Nature remains neutral with regard to jurisdictional claims in published maps and institutional affiliations.

\section{Submit your manuscript to a SpringerOpen ${ }^{\circ}$ journal and benefit from:}

- Convenient online submission

- Rigorous peer review

- Open access: articles freely available online

- High visibility within the field

- Retaining the copyright to your article

Submit your next manuscript at $\boldsymbol{\nabla}$ springeropen.com 